\title{
Growth and Device Performance of AlGaN/GaN Heterostructure with AlSiC Precoverage on Silicon Substrate
}

\author{
Jae-Hoon Lee ${ }^{1}$ and Jung-Hee Lee ${ }^{2}$ \\ ${ }^{1}$ Discrete Development Team, System LSI, Samsung Electronics Co., Ltd., Giheung 446-711, Republic of Korea \\ ${ }^{2}$ The School of Electronic Engineering \& Computer Science, Kyungpook National University, Daegu 702-701, Republic of Korea \\ Correspondence should be addressed to Jae-Hoon Lee; jaehoon03.lee@samsung.com
}

Received 2 May 2014; Revised 31 July 2014; Accepted 11 August 2014; Published 11 September 2014

Academic Editor: Simone Mazzucato

Copyright (c) 2014 J.-H. Lee and J.-H. Lee. This is an open access article distributed under the Creative Commons Attribution License, which permits unrestricted use, distribution, and reproduction in any medium, provided the original work is properly cited.

A crack-free $\mathrm{AlGaN} / \mathrm{GaN}$ heterostructure was grown on 4-inch $\mathrm{Si}$ (111) substrate with initial dot-like AlSiC precoverage layer. It is believed that introducing the AlSiC layer between AlN wetting layer and Si substrate is more effective in obtaining a compressively stressed film growth than conventional Al precoverage on Si surface. The metal semiconductor field effect transistor (MESFET), fabricated on the AlGaN/GaN heterostructure grown with the AlSiC layer, exhibited normally on characteristics, such as threshold voltage of $-2.3 \mathrm{~V}$, maximum drain current of $370 \mathrm{~mA} / \mathrm{mm}$, and transconductance of $124 \mathrm{mS} / \mathrm{mm}$.

\section{Introduction}

Group III-nitride semiconductors and their ternary solid solutions are very promising materials for both short wavelength optoelectronics and power electronic devices [14]. The $\mathrm{AlGaN} / \mathrm{GaN}$ heterostructure field effect transistors (HFETs) have a great potential for future high-frequency and high-power applications because of the intrinsic advantages of materials such as wide band gap, high breakdown voltage, and high electron peak velocity $[5,6]$. Si substrate is considered as a promising candidate, which may replace expensive and small-sized wafers such as sapphire and $\mathrm{SiC}$, even though the GaN layer grown on Si substrate has a large strain and dislocation due to a large lattice mismatch and thermal expansion coefficient difference between the grown GaN layer and the Si substrate $[7,8]$. The mismatch between thermal expansion coefficients is about $56 \%$, which induces a large tensile stress and may cause a severe crack generation in the grown $\mathrm{GaN}$ films during the cooling process after growth.

A GaN film grown directly on Si using conventional twostep method usually exhibits poor surface morphology and low crystal quality. In general, the GaN film grown on $\mathrm{Si}$ is very sensitive to growth conditions such as MOCVD chamber condition, substrate, III/V ratio, temperature, pressure, source, and layer materials. Therefore, various types of intermediate layer between the $\mathrm{GaN}$ epilayer and the $\mathrm{Si}$ substrate, such as $3 \mathrm{C}-\mathrm{SiC}, \mathrm{AlN}, \mathrm{GaAs}, \mathrm{AlAs}, \mathrm{Si}_{3} \mathrm{~N}_{4}$, and $\mathrm{r}$ $\mathrm{Al}_{2} \mathrm{O}_{3}$, have been studied to improve the crystalline quality of the GaN layer grown on Si substrate [9-12]. Steckl et al. [12] reported that (111) Si-on-insulator (SOI) structures can be converted to single crystalline $\mathrm{SiC}$ by carbonization of the thin $(<100 \mathrm{~nm}) \mathrm{Si}$ layer using rapid thermal chemical vapor deposition with mixtures of propane and $\mathrm{H}_{2}$ at atmospheric pressure. The structure of $\mathrm{GaN}$ films grown on (111) SiC SOI structure is comparable to $\mathrm{GaN}$ grown on sapphire substrates. This is because the single crystalline $\mathrm{SiC}$ interlayer decreases lattice mismatch between the grown GaN layer and the substrate. However, this method requires additional ex situ processes which cannot be always easily controlled. Since AlN has good wetting properties on Si substrate compared with other intermediate layers, the recent experimental results have concluded that an AlN buffer layer can alleviate the difficulties in growing the $\mathrm{GaN}$ layer on Si substrate. In addition, the $\mathrm{Al}$ precoverage on the surface of $\mathrm{Si}$ substrate is performed prior to the growth of the AlN layer to prevent 


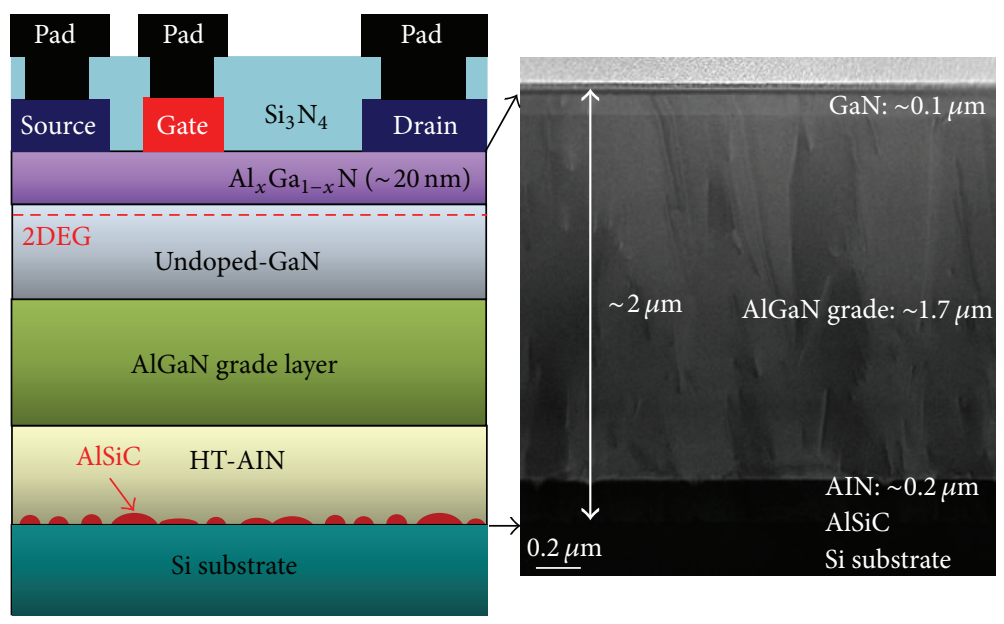

FIGURE 1: A schematic cross-sectional view and TEM image of the fabricated MESFET layer structure.

the formation of the amorphous $\operatorname{SiN}_{x}$ layer and hence to obtain high crystal quality $[13,14]$, because the formation of amorphous $\mathrm{SiN}_{x}$ in the initial stage of the growth passivates the surface and suppresses the GaN growth.

In this work, for the purpose of reducing the crack density in the AlGaN/GaN heterostructure grown on Si substrate, we have covered dot-like AlSiC layer on the surface of the $\mathrm{Si}$ substrate prior to the growth of the AlN wetting layer. The device performances of the normally on AlGaN/GaN HFETs fabricated on the $\mathrm{Si}$ substrate grown with $\mathrm{AlSiC}$ precoverage were also demonstrated.

\section{Experiments}

The AlGaN/GaN heterostructure investigated in this work was grown on 4-inch (111) p-type Si substrates by metal organic chemical vapor deposition (MOCVD). Trimethylgallium (TMGa), trimethylaluminum (TMAl), carbon tetrabromide $\left(\mathrm{CBr}_{4}\right)$, ditertiarybutylsilane (DTBSi), and ammonia $\left(\mathrm{NH}_{3}\right)$ were used for the precursors of $\mathrm{Ga}, \mathrm{Al}, \mathrm{C}, \mathrm{Si}$, and $\mathrm{N}$, respectively [15]. Prior to the growth of AlN wetting layer, the Si substrate was baked in an $\mathrm{H}_{2}$ ambient at $1100^{\circ} \mathrm{C}$ for $10 \mathrm{~min}$ to remove the native oxide and then presurface coverage on the $\mathrm{Si}$ substrate with $\mathrm{AlSiC}$ was performed for 60 seconds in order to prevent formation of amorphous $\mathrm{SiN}_{x}$ layer. For comparison, the heterostructure with conventional Al presurface coverage was also grown. The layer structure with total thickness of about $2 \mu \mathrm{m}$ consists of $200 \mathrm{~nm}$ thick high temperature- (HT-) AlN layer, $1.7 \mu \mathrm{m}$ thick AlGaN graded layer, $100 \mathrm{~nm}$ thick GaN layer, and $20 \mathrm{~nm}$ thick AlGaN barrier in growth sequence [16]. The $\mathrm{Al}$ content in the $\mathrm{AlGaN}$ barrier is $20 \%$, determined by high-resolution X-ray diffraction (XRD). The mobility and the density of the two-dimensional electron gas (2DEG) formed at the AlGaN/GaN heterointerface were $1100 \mathrm{~cm}^{2} / \mathrm{V} \cdot \mathrm{s}$ and $8 \times 10^{12} / \mathrm{cm}^{2}$, respectively. For the device fabrication, the active region of the device was defined by inductively coupled plasma (ICP) reactive ion etching using a $\mathrm{BCl}_{3} / \mathrm{Cl}_{2}$ gas mixture. After opening contact holes, $\mathrm{Ti} / \mathrm{Al} / \mathrm{Ni} / \mathrm{Au}$ metal layer for Ohmic contact was deposited and followed by rapid thermal annealing at $850^{\circ} \mathrm{C}$ for $30 \mathrm{~s}$ in $\mathrm{N}_{2}$ ambient. The specific contact resistance of $2 \times 10^{-5} \Omega \cdot \mathrm{cm}^{-2}$ was obtained for the annealed sample using transmission line measurements (TLM). After depositing Ni/Au for the gate metal, $\mathrm{Si}_{3} \mathrm{~N}_{4}$ interdielectric layer with thickness of $800 \mathrm{~nm}$ was deposited to cover the entire surface of the device. Ti/Al pad metals were finally deposited to connect the gate and the source/drain region. The current-voltage $(I-V)$ characteristics were measured by using Agilent 4155 parameter analyzer and STI curve tracer 5000E. A schematic crosssection and the transmission electron microscope (TEM) image of the fabricated metal semiconductor field effect transistor (MESFET) are shown in Figure 1.

\section{Results and Discussion}

The existence of AlSiC precoverage layer on Si surface was confirmed by the secondary ion mass spectroscope (SIMS) analysis as shown in Figure 2(a). For the purpose of finding the atomic composition of the AlSiC layer, a reference AlSiC layer with thickness of $20 \mathrm{~nm}$ was grown on Si substrate under the same growth condition as the $\mathrm{AlSiC}$ precoverage layer in real epitaxial structure. X-Ray photoelectron spectroscopy (XPS) analysis for this AlSiC layer reveals that $\mathrm{Al}, \mathrm{Si}, \mathrm{C}$, and $\mathrm{O}$ atoms exist in the $\mathrm{AlSiC}$ layer with atomic composition of 37, 31, 23, and 9\%, respectively, as shown in Figure 2(b). High concentrations of carbon and $\mathrm{Si}$ atoms were observed at interface between AlN buffer layer and Si substrate. The slight $\mathrm{C}, \mathrm{Ga}$, and $\mathrm{Al}$ peaks also appear to be within the silicon bulk, which is due to diffusion at high temperature growth condition. Figures 2(c) and 2(d) show atomic force microscopy (AFM) images for the surface of the Si substrate after deposition of $\mathrm{Al}$ and $\mathrm{AlSiC}$ precoverage layer with corresponding rms roughness of 0.5 and $3.9 \mathrm{~nm}$, respectively. It is noticed that the grain size of the randomly distributed $\mathrm{AlSiC}$ precoverage layer is larger than that of the $\mathrm{Al}$ precoverage.

The growth with AlSiC precoverage resulted in crack-free surface while the layer with Al precoverage showed many cracks on the surface, as shown in Figure 3. This probably 


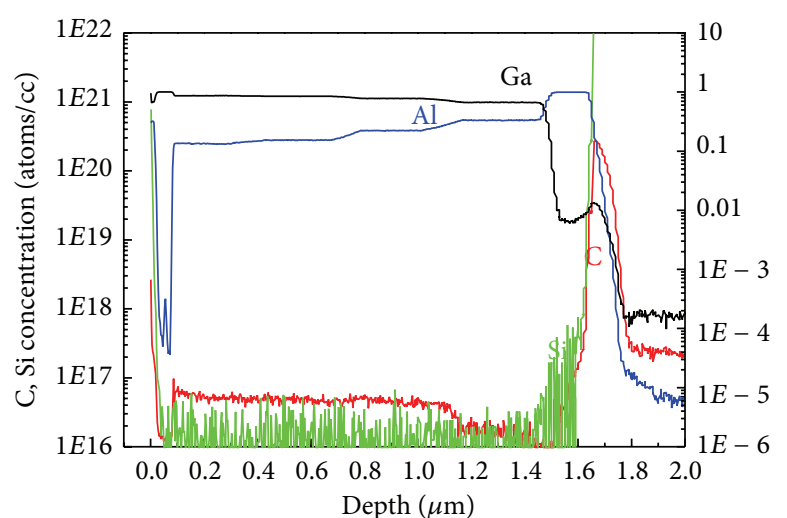

(a)

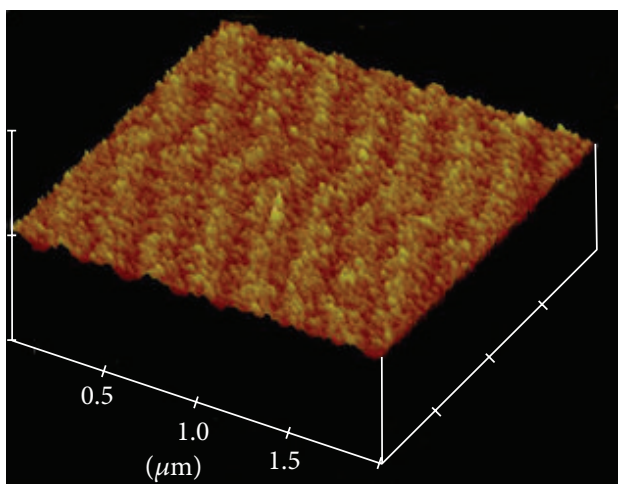

(c)

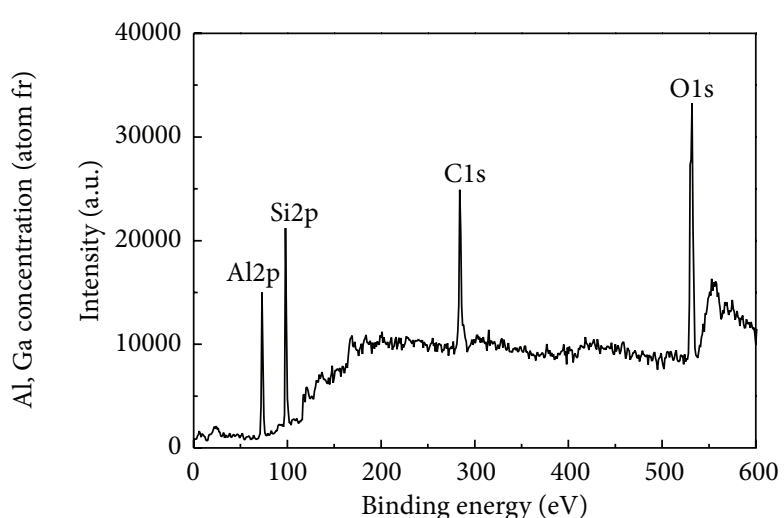

(b)

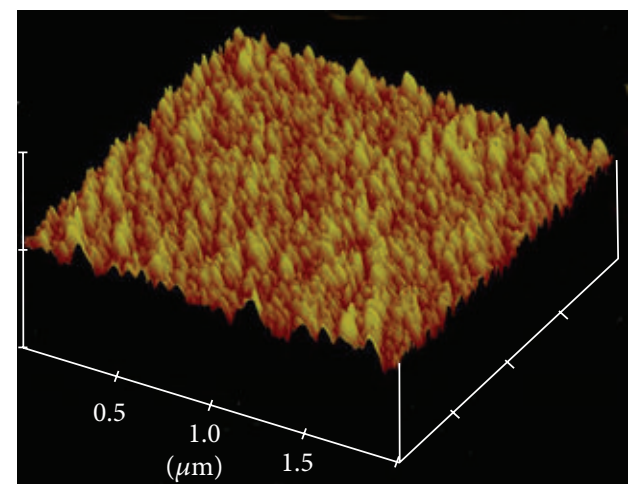

(d)

FIGURE 2: (a) SIMS profile of film grown on Si substrate with AlSiC precoverage layer in real epitaxial layer. (b) XPS measurement of $20 \mathrm{~nm}$ thick reference AlSiC film. (c) AFM images of Si surface covered with Al precoverage layer. (d) AFM images of Si surface covered with AlSiC precoverage layer.

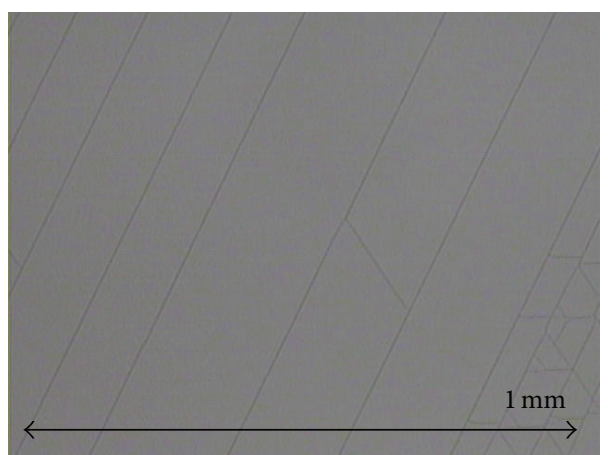

(a)

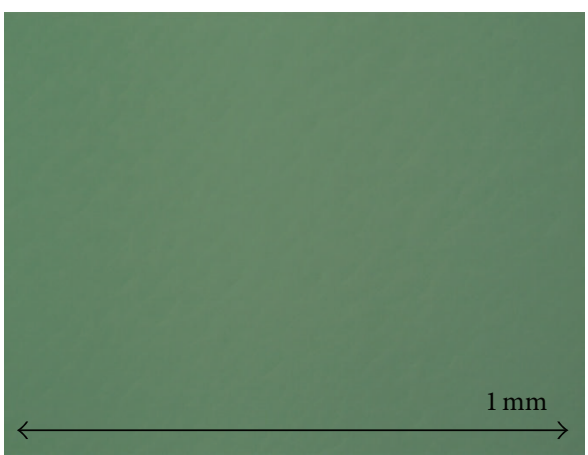

(b)

FIGURE 3: Optical photography of AlGaN/GaN surface grown on Si substrate with $\mathrm{Al}$ (a) and AlSiC precoverage interlayer (b).

explains that $\mathrm{AlSiC}$ precoverage is effective in compensating the tensile stress in the GaN layer grown on Si substrate. The Raman scattering spectra shown in Figure 4(a) exhibit peak shift at frequencies of 567.08 and $568.53 \mathrm{~cm}^{-1}$ for the grown film with $\mathrm{Al}$ and $\mathrm{AlSiC}$ precoverage, corresponding to the calculated biaxial stresses of 0.099 and $-0.240 \mathrm{GPa}$, respectively [17]. This indicates that the biaxial stress in the AlGaN/GaN heterostructure grown on $\mathrm{Si}$ substrate with $\mathrm{AlSiC}$ precoverage is compressive while that with $\mathrm{Al}$ precoverage still remains tensile, considering the reference value of $567.5 \mathrm{~cm}^{-1}$ for the freestanding GaN. It is believed that the insertion of AlSiC precoverage layer gives rise to strong compressive stress in the GaN film grown on Si substrate during the high temperature growth, which sufficiently overcomes the tensile stress caused by cooling down and remains compressive even after completing the growth. Photoluminescence mapping in inset of Figure 4(a) showed the average peek wavelength at $361.5 \mathrm{~nm}$, which belongs to the shifted wavelength for 


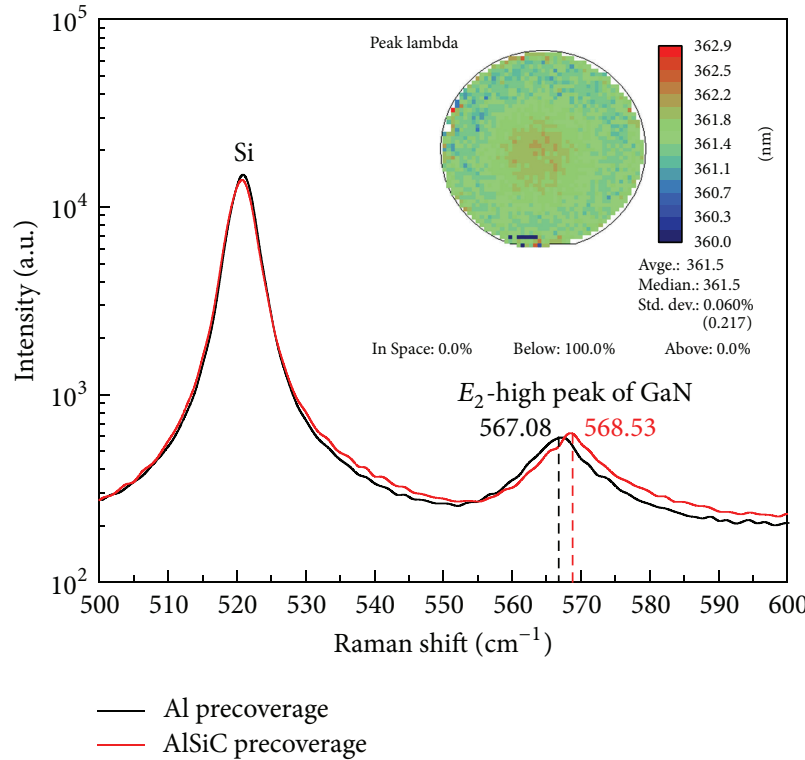

(a)

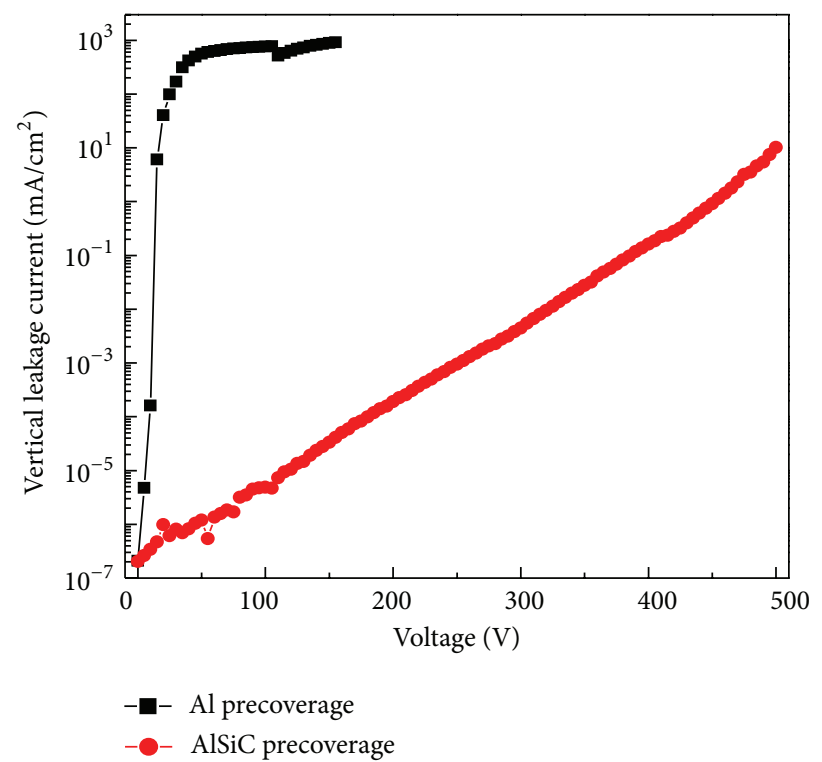

(b)

FIGURE 4: (a) Raman scattering spectra of $\mathrm{AlGaN} / \mathrm{GaN}$ layers grown on Si substrate with $\mathrm{Al}$ and $\mathrm{AlSiC}$ precoverage layer. The inset shows the map image of wavelength for grown films with AlSiC precoverage layer. (b) Vertical leakage current of AlGaN/GaN layers grown on Si substrate with $\mathrm{Al}$ and $\mathrm{AlSiC}$ precoverage layer.

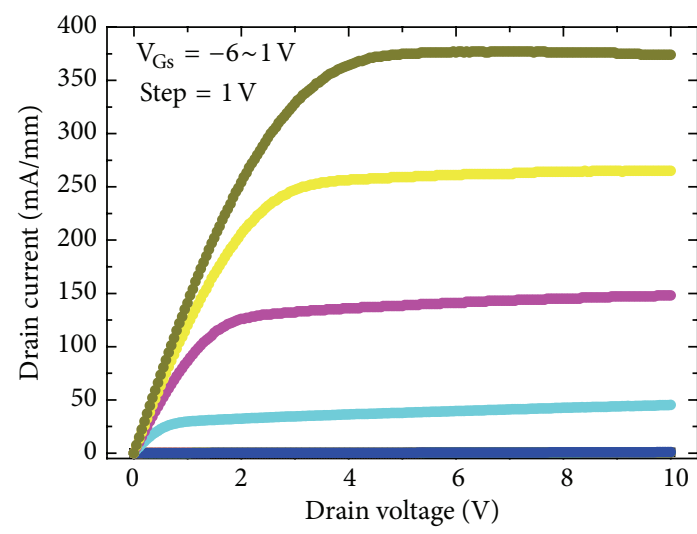

(a)

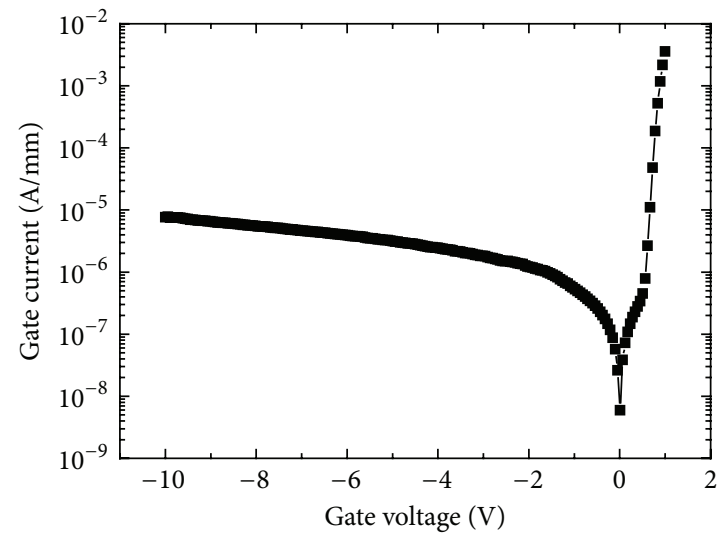

(c)

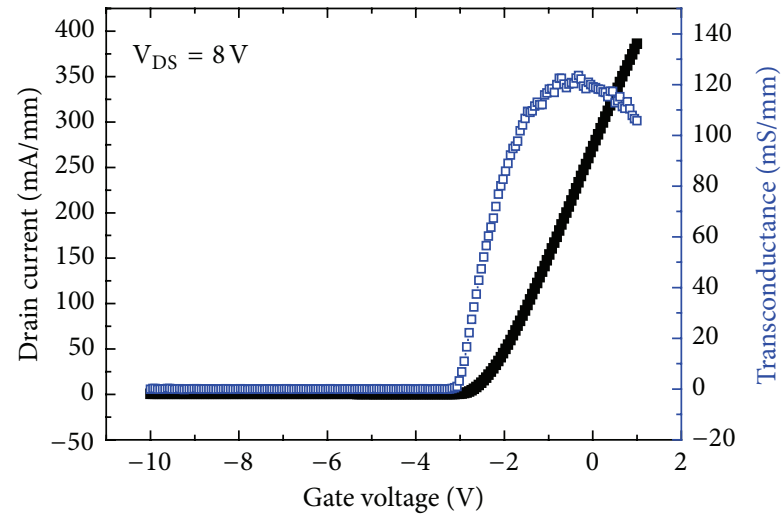

(b)

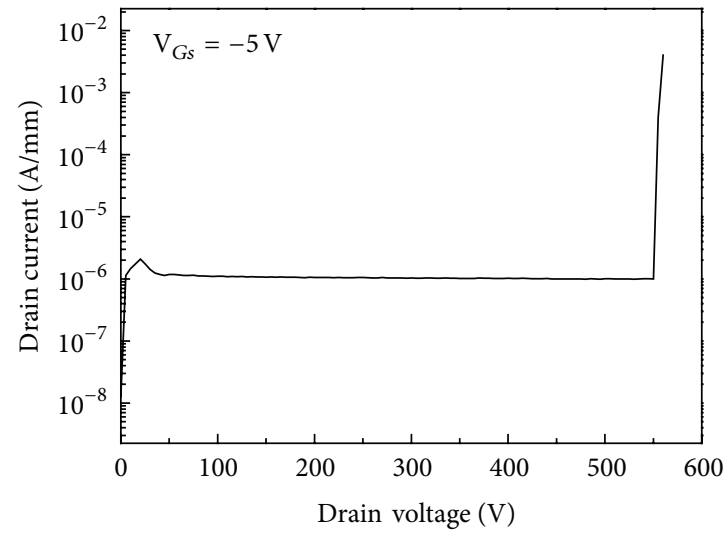

(d)

FIGURE 5: $I$ - $V$ characteristics of the fabricated device with AlSiC precoverage layer. (a) Drain current, (b) transfer characteristics, (c) gate leakage current, and (d) breakdown voltage. 
the compressively stressed GaN layer. On the other hand, the films with $\mathrm{Al}$ precoverage were not able to sufficiently overcome the tensile stress which resulted in generation of crack on GaN surface due to different thermal expansion coefficient after cooling down. Figure 4(b) showed the vertical leakage current-voltage $(I-V)$ characteristics for both AlGaN/GaN heterostructure grown on $\mathrm{Si}$ substrate with $\mathrm{Al}$ and $\mathrm{AlSiC}$ precoverage layer. The leakage current was measured by using a circular type pattern with diameter of $100 \mu \mathrm{m}$ between Ohmic contact pads and Si substrate. As shown in Fig ure 4(b), the film with $\mathrm{Al}$ precoverage layer exhibits the short characteristics due to the crack path. On the other hand, the film with $\mathrm{AlSiC}$ precoverage layer exhibits relatively higher semi-insulating characteristics of $3 \times 10^{8} \Omega(1 \mu \mathrm{A}$ at $300 \mathrm{~V})$, which make it attractive for high-power application.

Figure 5 shows the $I-V$ characteristics for the normally on AlGaN/GaN HFET fabricated on the grown AlGaN/GaN heterostructure with the AlSiC precoverage on the $\mathrm{Si}$ substrate. The gate length, the gate width, and the gateto-drain distance of both devices were 2, 140, and $20 \mu \mathrm{m}$, respectively. The total area of the device was $500 \times 500 \mu \mathrm{m}^{2}$. The maximum drain current $\left(I_{\mathrm{dmax}}\right)$ and the specific on stateresistance $\left(R_{\mathrm{ON}}\right)$ of the normally on HFET are $370 \mathrm{~mA} / \mathrm{mm}$ and $5 \mathrm{~m} \Omega \cdot \mathrm{cm}^{2}$, respectively, as shown in Figure 5(a). The threshold voltage and the maximum transconductance $(\mathrm{Gm})$ of device at a fixed $V_{\mathrm{DS}}$ of $8 \mathrm{~V}$ are $-2.3 \mathrm{~V}$ and $124 \mathrm{mS} / \mathrm{mm}\left(I_{\mathrm{DS}^{-}}\right.$ $V_{\mathrm{GS}}$ ), respectively, as shown in Figure 5(b). The gate leakage current is $-5 \mu \mathrm{A}$ at gate voltage of $-10 \mathrm{~V}$ (Figure $5(\mathrm{c})$ ), which is comparable to that of AlGaN/GaN HFET grown on the sapphire substrate [18]. In addition, the offstate breakdown voltage of the device is as high as $550 \mathrm{~V}$ (Figure 5(d)), even though no additional processes are applied to increase the breakdown voltage, which demonstrates that the AlGaN/GaN HFET with the AlSiC precoverage on the Si substrate has a great potential application to the high-power device.

\section{Conclusion}

To obtain a crack-free AlGaN/GaN heterostructure grown on $\mathrm{Si}$ substrate, we proposed the insertion of the AlSiC precoverage layer between $\mathrm{AlN}$ and $\mathrm{Si}$ substrate. The AlSiC precoverage layer generates the compressive stress in the film grown on Si substrate during the high temperature growth, which resulted in crack-free films due to compensation of tensile stress after finishing epitaxial growth. The fabricated normally on HFET exhibits a threshold voltage of $-2.3 \mathrm{~V}, I_{\mathrm{dmax}}$ of $370 \mathrm{~mA} / \mathrm{mm}, R_{\mathrm{ON}}$ of $5 \mathrm{~m} \Omega \cdot \mathrm{cm}^{2}$, and $\mathrm{Gm}$ of $124 \mathrm{mS} / \mathrm{mm}$.

\section{Conflict of Interests}

The authors declare that there is no conflict of interests regarding the publication of this paper.

\section{Acknowledgments}

This work was partly supported by Kyungpook National University Research Fund 2012, the BK21 Plus funded by the Ministry of Education (21A20131600011), the IT R\&D Program of MOTIE/KEIT (10048931), and the National Research Foundation of Korea (NRF) Grant funded by the Korean Government (MSIP) (nos. 2008-0062617 and 20110016222).

\section{References}

[1] S. Nakamura, M. Senoh, S.-I. Nagahama et al., "High-power, long-lifetime InGaN multi-quantum-well-structure laser diodes," Japanese Journal of Applied Physics, vol. 36, no. 8, pp. L1059-L1061, 1997.

[2] J.-H. Lee, D.-Y. Lee, B.-W. Oh, and J.-H. Lee, "Comparison of InGaN-based LEDs grown on conventional sapphire and cone-shape-patterned sapphire substrate," IEEE Transactions on Electron Devices, vol. 57, no. 1, pp. 157-163, 2010.

[3] J. H. Lee, J. T. Oh, S. B. Choi, Y. C. Kim, and H. I. Cho, "Enhancement of InGaN-based vertical LED with concavely patterned surface using patterned sapphire substrate," IEEE Photonics Technology Letters, vol. 20, no. 5, pp. 345-347, 2008.

[4] Y. Uemoto, M. Hikita, H. Ueno et al., "Gate injection transistor (GIT) - a normally-off AlGaN/GaN power transistor using conductivity modulation," IEEE Transactions on Electron Devices, vol. 54, no. 12, pp. 3393-3399, 2007.

[5] O. Ambacher, J. Smart, J. R. Shealy et al., "Two-dimensional electron gases induced by spontaneous and piezoelectric polarization charges in N- And Ga-face AIGaN/GaN heterostructures," Journal of Applied Physics, vol. 85, no. 6, pp. 3222-3233, 1999.

[6] Y.-F. Wu, D. Kapolnek, J. P. Ibbetson, P. Parikh, B. P. Keller, and U. K. Mishra, "Very-high power density AlGaN/GaN HEMT's," IEEE Transactions on Electron Devices, vol. 48, no. 3, pp. 586590, 2001.

[7] F. Semond, P. Lorenzini, N. Grandjean, and J. Massies, "High-electron-mobility AlGaN/GaN heterostructures grown on Si(111) by molecular-beam epitaxy," Applied Physics Letters, vol. 78, no. 3, pp. 335-337, 2001.

[8] P. Kung, A. Saxler, X. Zhang et al., "High quality AIN and GaN epilayers grown on (001) sapphire, (100), and (111) silicon substrates," Applied Physics Letters, vol. 66, pp. 2958-2960, 1995.

[9] Y. Nakada, I. Aksenov, and H. Okumura, "GaN heteroepitaxial growth on silicon nitride buffer layers formed on Si (111) surfaces by plasma-assisted molecular beam epitaxy," Applied Physics Letters, vol. 73, no. 6, pp. 827-829, 1998.

[10] L. Wang, X. Liu, Y. Zan et al., "Wurtzite GaN epitaxial growth on a $\mathrm{Si}(001)$ substrate using $\gamma-\mathrm{Al}_{2} \mathrm{O}_{3}$ as an intermediate layer," Applied Physics Letters, vol. 72, no. 1, pp. 109-111, 1998.

[11] A. le Louarn, S. Vézian, F. Semond, and J. Massies, "AlN buffer layer growth for GaN epitaxy on (111) Si: Al or N first?" Journal of Crystal Growth, vol. 311, no. 12, pp. 3278-3284, 2009.

[12] A. J. Steckl, J. Devrajan, C. Tran, and R. A. Stall, "SiC rapid thermal carbonization of the (111)Si semiconductor-on-insulator structure and subsequent metalorganic chemical vapor deposition of GaN," Applied Physics Letters, vol. 69, no. 15, pp. 22642266, 1996.

[13] I.-H. Lee, S. J. Lim, and Y. Park, "Growth and optical properties of GaN on $\mathrm{Si}\left(\begin{array}{lll}1 & 1 & 1\end{array}\right)$ substrates," Journal of Crystal Growth, vol. 235, no. 1-4, pp. 73-78, 2002.

[14] P. Chen, R. Zhang, Z. M. Zhao et al., "Growth of high quality GaN layers with AlN buffer on $\mathrm{Si}(111)$ substrates," Journal of Crystal Growth, vol. 225, no. 2-4, pp. 150-154, 2001. 
[15] J.-H. Lee, J.-H. Jeong, and J.-H. Lee, "Enhanced electrical characteristics of AlGaN-based SBD with in situ deposited silicon carbon nitride cap layer," IEEE Electron Device Letters, vol. 33, no. 4, pp. 492-494, 2012.

[16] K. Cheng, M. Leys, S. Degroote et al., "Flat GaN epitaxial layers grown on $\mathrm{Si}(111)$ by metalorganic vapor phase epitaxy using step-graded AlGaN intermediate layers," Journal of Electronic Materials, vol. 35, no. 4, pp. 592-598, 2006.

[17] S. Tripathy, S. J. Chua, P. Chen, and Z. L. Miao, "MicroRaman investigation of strain in $\mathrm{GaN}$ and $\mathrm{Al}_{x} \mathrm{Ga}_{1-x} \mathrm{~N} / \mathrm{GaN}$ heterostructures grown on $\mathrm{Si}(111)$," Journal of Applied Physics, vol. 92, no. 7, pp. 3503-3510, 2002.

[18] J.-H. Lee, J.-H. Jeong, and J.-H. Lee, "Normally off GaN power MOSFET grown on sapphire substrate with highly resistive undoped buffer layer," IEEE Electron Device Letters, vol. 33, no. 10, pp. 1429-1431, 2012. 

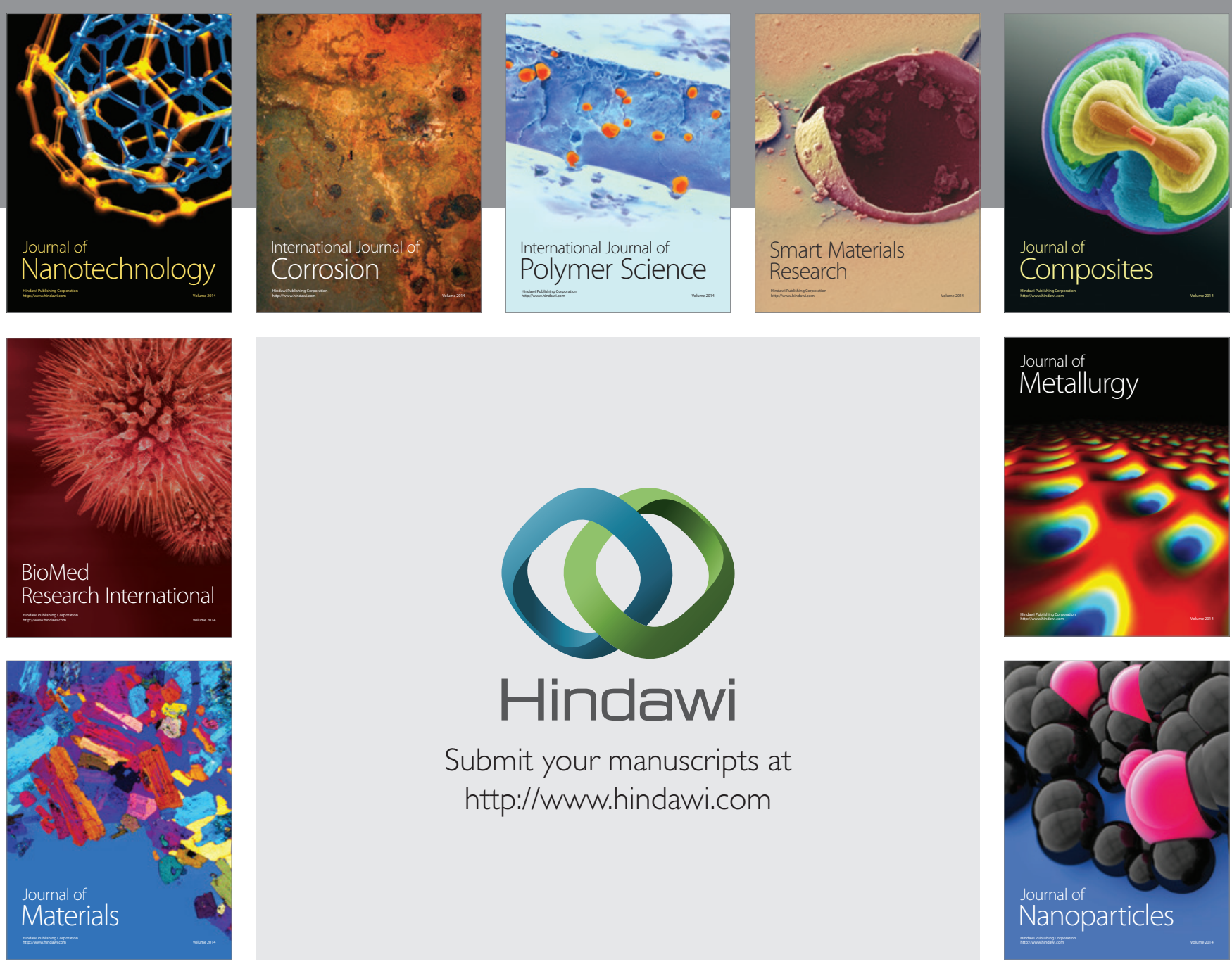

Submit your manuscripts at http://www.hindawi.com
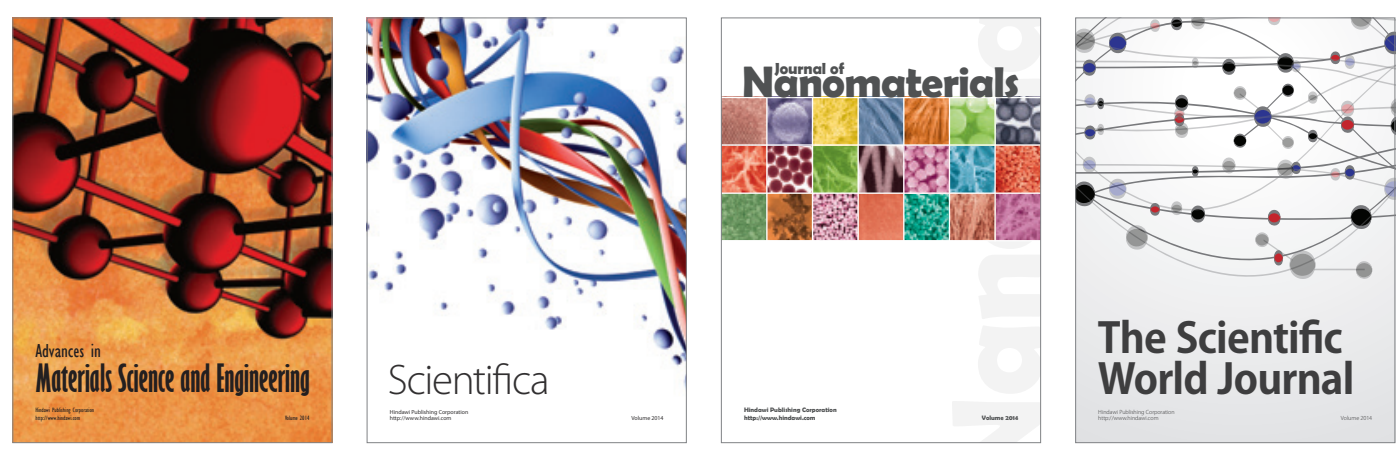

\section{The Scientific World Journal}
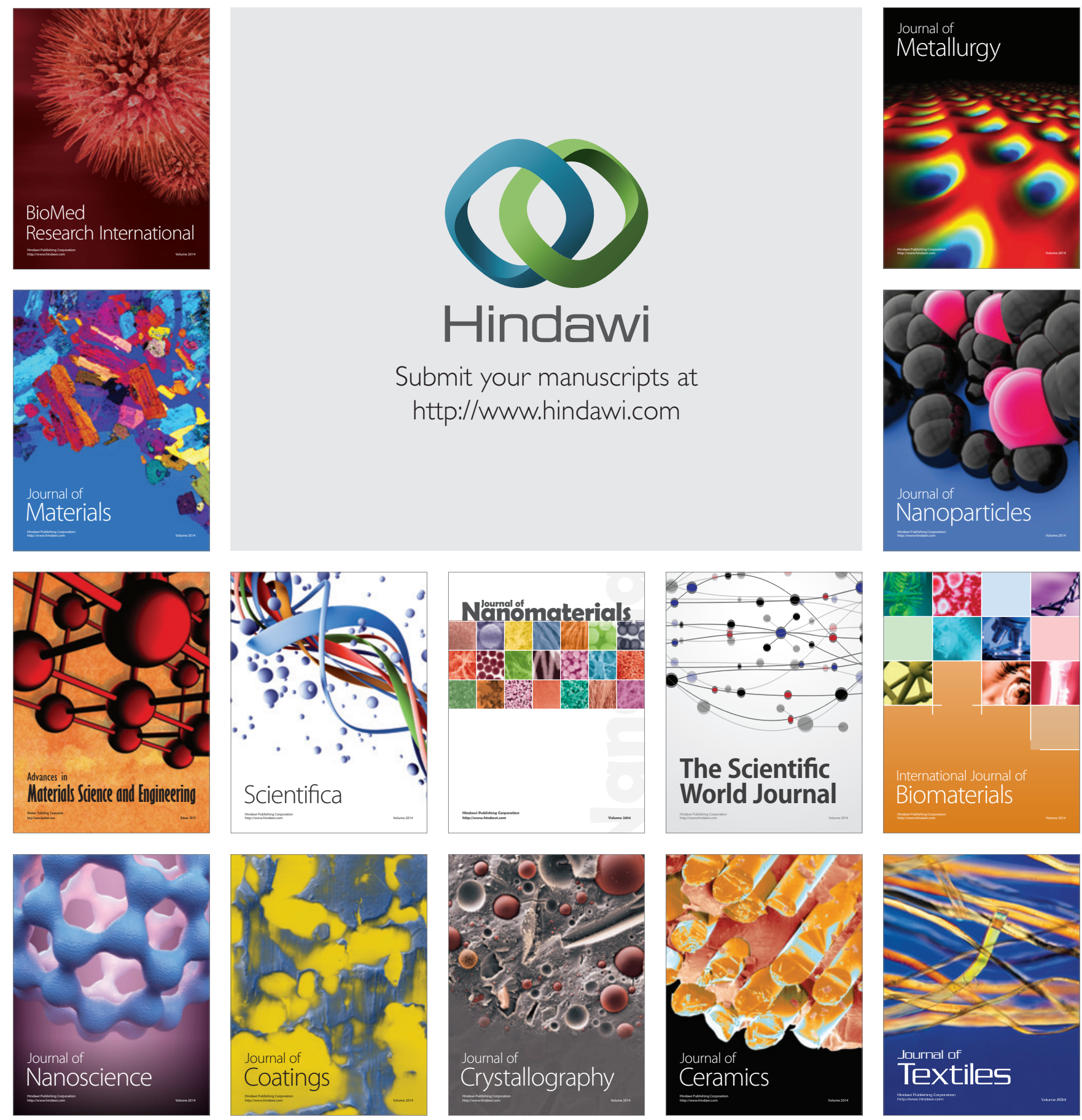